\title{
Utility of external and internal magnets to facilitate bile duct cannulation by changing the position of the papilla
}

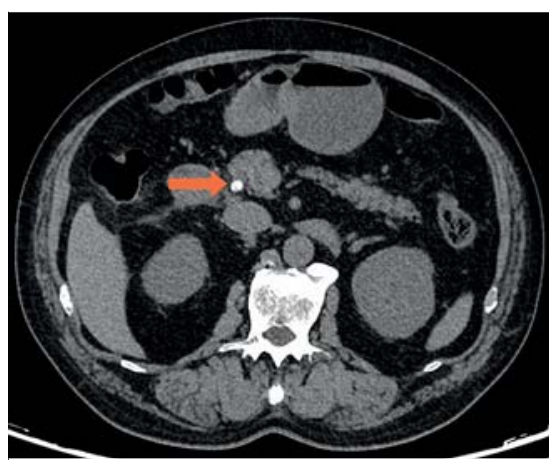

- Fig. 1 Nonenhanced abdominal computed tomography scan indicating the presence of an 8-mm stone (yellow arrow) in the distal common bile duct of a 75-year-old man.

A 75-year-old man attended the emergency department complaining of upper abdominal colic accompanied by nausea and cold sweating for 24 hours. Physical examination found that there was mild tenderness and tension in the upper region of his abdomen. Several of his liver function test and blood chemistry values were abnormal: neutrophil count

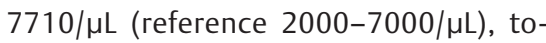
tal bilirubin $2.1 \mathrm{mg} / \mathrm{dL}$, direct bilirubin $1.3 \mathrm{mg} / \mathrm{dL}$, pancreatic lipase $2085 \mathrm{IU} / \mathrm{L}$. In addition, acute inflammatory markers, including procalcitonin $(0.63 \mathrm{ng} / \mathrm{mL}), \mathrm{IL}-6$ $(287 \mathrm{pg} / \mathrm{mL})$, and C-reactive protein $(59.1 \mathrm{mg} / \mathrm{mL})$, were all elevated. A nonenhanced abdominal computed tomography scan indicated the presence of an 8-mm stone in the distal common bile duct ( $\triangleright$ Fig. 1).

Endoscopic retrograde cholangiopancreatography (ERCP) was performed on the second day after admission. The duodenoscope reached the descending duodenum smoothly. However, as the angle between the bile duct and cannulation was almost a right angle, possibly caused by a diverticulum, an experienced endoscopist failed to complete biliary cannulation after several attempts (> Fig. 2). Several days later, a second try was
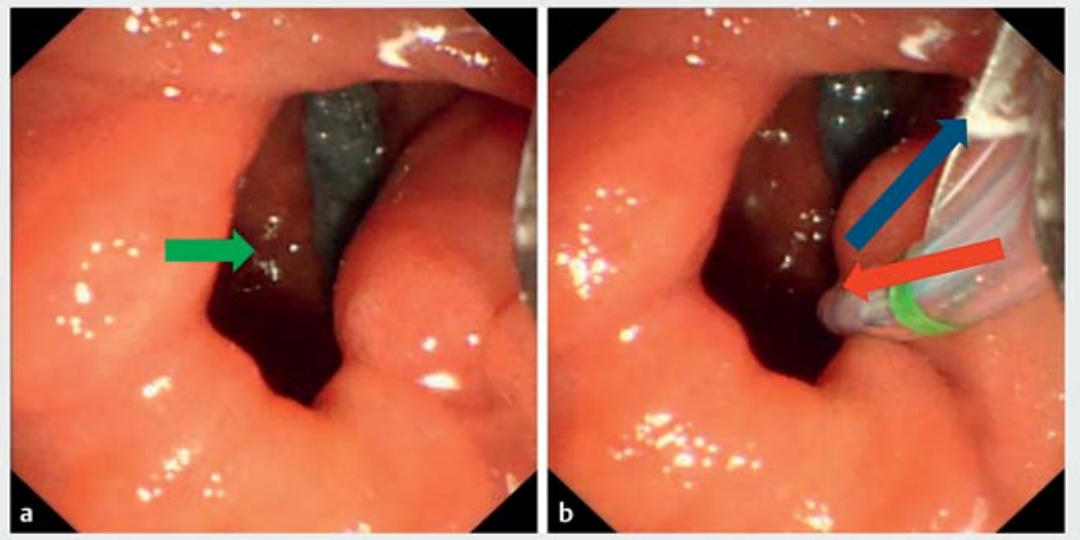

- Fig. 2 Biliary cannulation was not completed at the first session. a A diverticulum (green arrow) is seen beside the papilla. $\mathbf{b}$ The angle between the bile duct (blue arrow) and cannulation (red arrow) was almost a right angle.

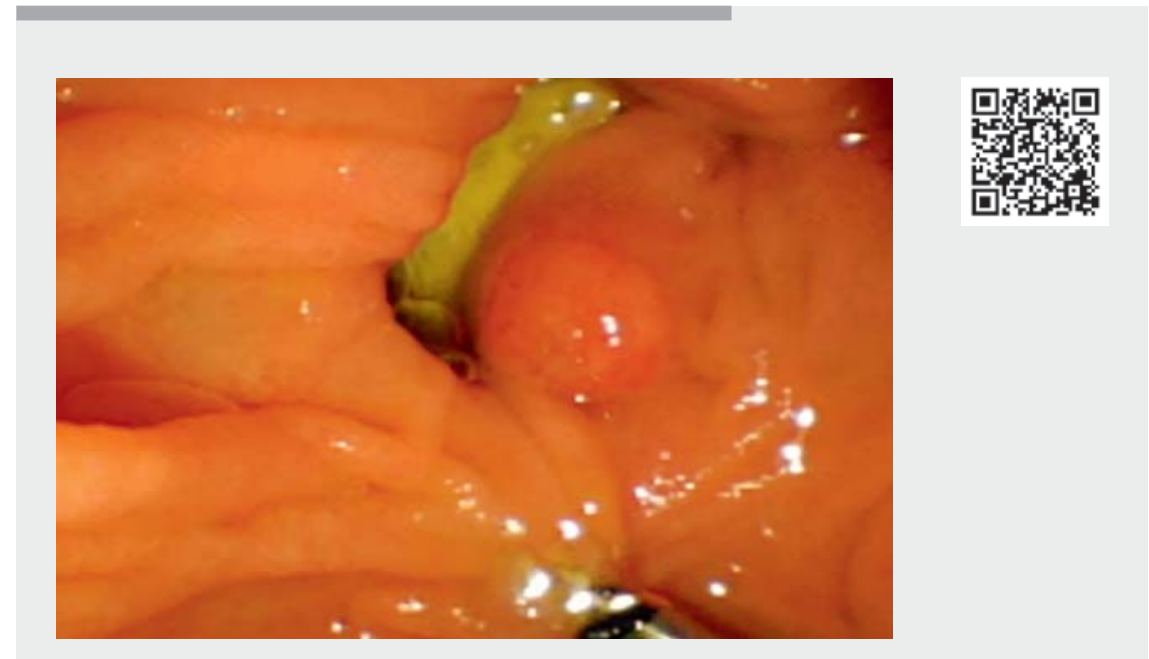

$\checkmark$ Video 1 External and internal magnets were used to facilitate bile duct cannulation by changing the position of the papilla.

made, this time using magnets to help to tackle the difficult papilla ( $\triangleright$ Video 1 ). A magnetic bead was fixed next to the papilla and a powerful magnet placed externally ( $\mathbf{F i g . 3 a , b ) . ~ T h r o u g h ~ t h e ~}$ attraction between the magnets, the angle was changed and the biliary cannulation was then successfully performed ( Fig.3c,d). Following cannulation, the sphincter was cut about $5 \mathrm{~mm}$ using blended current. Finally, the stone was extracted using a stone basket, and the filling defect disappeared (\$ Fig.3e,f). There were no complications.

Reports exist of magnets playing an important role in endoscopic surgery [1,2]. In the present case, biliary cannulation that was difficult using the conventional 

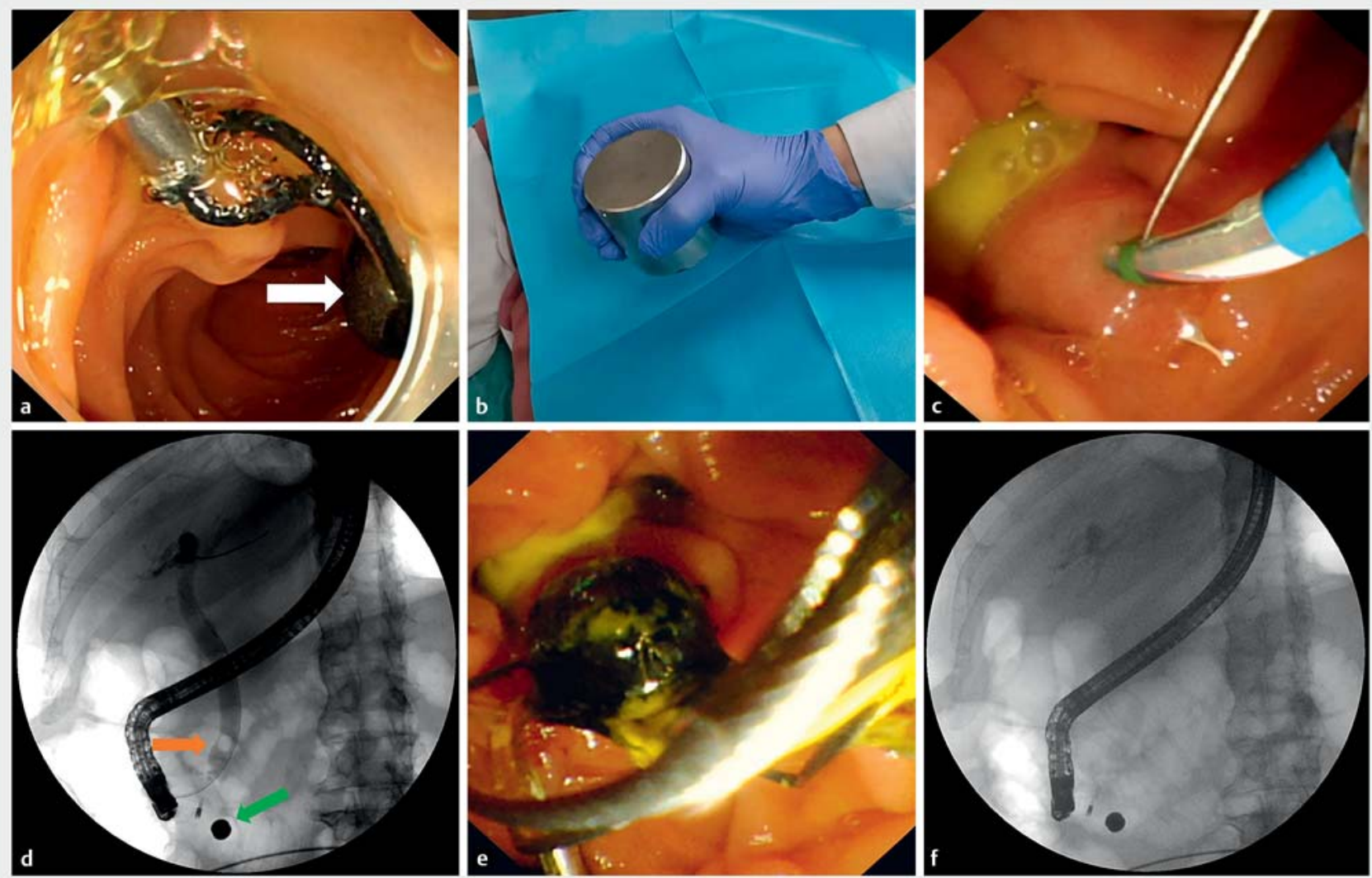

Fig. 3 The process of successful biliary cannulation. a A magnetic bead (white arrow) was fixed next to the papilla. b A powerful magnet was placed externally. $\mathbf{c}$ Biliary cannulation was successfully performed. $\mathbf{d}$ Fluoroscopic image: the yellow arrow indicates the stone and the green arrow the magnetic bead. $\mathbf{e}$ The stone was extracted. $\mathbf{f}$ The filling defect disappeared.

technique was achieved successfully in a short time with the help of magnets. The advantage of the magnets was that the direction and force of traction could be easily adjusted, which was helpful in tackling the difficult papilla. This technique could be applied to other, similar situations during ERCP.

Endoscopy_UCTN_Code_TTT_1AR_2AK

Funding

Sichuan University, West China Hospital, 1.3.5 Project for Disciplines of Excellence ZYJC21011

\section{Competing interests}

The authors declare that they have no conflict of interest.
The authors

\section{Yi Mou, Long He, Bing $\mathrm{Hu}{ }^{\circ}$}

Department of Gastroenterology, West China Hospital, Sichuan University Chengdu, Sichuan, P. R. China

\section{Corresponding author}

\section{Bing Hu, MD}

West China Hospital, Sichuan University, No. 37, Guo Xue Alley, Wuhou District, Chengdu City, Sichuan Province, P. R. China hubingnj@163.com

\section{References}

[1] Guo L], Ye L, Huang ZY et al. Magnetic beads-assisted endoscopic submucosal dissection of duodenal heterotopic gastric mucosa with fibrosis. Endoscopy 2019; 51: E113-E115

[2] Jiang XM, Yamamoto K, Tsuchiya T et al. Magnetic compression anastomosis for biliary obstruction after partial hepatectomy. Endoscopy 2018; 50: E144-E145

\section{Bibliography}

Endoscopy 2022; 54: E715-E716

DOI 10.1055/a-1756-4349

ISSN 0013-726X

published online 7.3.2022

(c) 2022. Thieme. All rights reserved.

Georg Thieme Verlag KG, Rüdigerstraße 14, 70469 Stuttgart, Germany 